\title{
Ectopic Paratesticular Adrenal Gland in a Fetus: Fortuity or Morphological Cues About the Cause of Death
}

\author{
Stefania Erra*, Silvio Modena, Giulia Speranza \\ Department of Surgical Pathology, Santo Spirito Hospital, Casale Monferrato (Al), Italy \\ Email address: \\ stefania.erra@virgilio.it (S. Erra), serra@aslal.it (S. Erra) \\ ${ }^{*}$ Corresponding author \\ To cite this article: \\ Stefania Erra, Silvio Modena, Giulia Speranza. Ectopic Paratesticular Adrenal Gland in Fetus a: Fortuity or Morphological Cues About the \\ Cause of Death. International Journal of Clinical and Developmental Anatomy. Vol. 2, No. 2, 2016, pp. 14-16. \\ doi: $10.11648 /$ j.ijcda.20160202.11
}

Received: March 18, 2016; Accepted: May 10, 2016; Published: June 3, 2016

\begin{abstract}
In this paper, a case of ectopic supernumerary paratesticular adrenal gland in a 18 week fetus was described. Ectopic adrenal tissue has been described in male young patients along the spermatic cord during groin surgical exploration. The first description was made from Morgagni in 1740 and about one hundred of cases have been reported in international literature, above all in pediatric patients that underwent to surgical intervention on inguinal region. 80 cases of ectopic adrenal tissue have been detected in gonadal region, with a male prevalence in scrotal location. Our report regards a perinatal autopsy of a male fetus died during the second trimester of gestation for placental infection. We speculate on the importance of this morphological detection aimed at reconstruction of the pathogenesis of death.
\end{abstract}

Keywords: Adrenal Gland, Ectopic, Perinatal Autopsy

\section{Introduction}

Ectopic tissue is a common reply during histological examinations of bioptical or surgical samples [1]. Ectopic wellformed organs represent rare findings, previously detected during autopsies. The most frequently described ectopic and supernumerary organ in humans is spleen. It has also reported in a scrotal site of a child [2]. Ectopic supernumerary adrenal has been considered a very rare detection, even if adrenal tissue in scrotal and paragonadal sites has been reported in one hundred of young and pediatric patients [3].

We report a case of ectopic supernumerary adrenal gland encountered in pelvic paratesticular site during a male eighteen week fetus autopsy with adrenal gland bilateral hyperplasia, peritoneal and chest lymphangioma. We speculate on relationship between these findings and the demonstrated placental infection to assume a possible teratogenic role of some viral agents in second gestational trimester.

\section{Case Presentation}

We describe autopsy findings regarding an eighteen week male fetus died for suspected placental infection. Maternal clinic and obstetric history didn't seem suspect for chromosomal anomalies. The mother of the fetus is a 35 years old Arab woman with other two healthy children and no problems in previous pregnancies. In fact, her fetus wasn't considered at risk for chromosomal anomalies and she wasn't submitted to amniocentesis. She presented in our hospital with high fever and abdominal pains, resistant to antibiotics and paracetamol. Ultrasound investigation revealed strong uterine contraction ending with the preterm birth and the consequent fetus death.

Anthropometric evaluation and external examination of the fetus confirmed sex and a gestational age of 18 weeks, as reported by obstetrics. Autopsy findings showed normal conformation and location of internal organs, with the presence of brain parenchymal and meningeal bleeding, consequence of the sudden child expulsion. During the search of the testis in the pelvic area near the orifice of the inguinal canal, we found a little nodule adherent to right testis, seeming to be a lymph node or an accessory gonad. Microscopic evaluation of this nodule revealed that it was consisted with a well-formed adrenal gland of a diameter of 2 millimeter composed by the cortical area only, as it can be 
detected in normally located adrenal glands in the second trimester of gestational age (fig. 1). In fact, maturation of medullary zone in adrenals represents a late event during human organogenesis. Even if it can be observed little dark cells from neural crest migrating into adrenal parenchyma in early embryos, after only the $25^{\text {th }}$ week of gestation a medullary area can be recognized in adrenal gland [4]. During the evaluation of the fetal adrenals, we encountered bilateral adrenal hyperplasia with a high weight for the gestational age, corresponding to a $26^{\text {th }}$ week of gestation, and a histological evidence of nodular hyperplasia of the cortex. No other anatomic or tissue alterations were found, except for the presence of lymphangiomas microscopically encountered in the peritoneum (fig. 2) and in the wall of ascending aorta (fig. 3), in absence of cardiac or vascular malformations. Placental investigation detected leucocyte infiltration of decidual plate, constituted by lymphocytes and monocytes, without involvement of the umbilical cord.

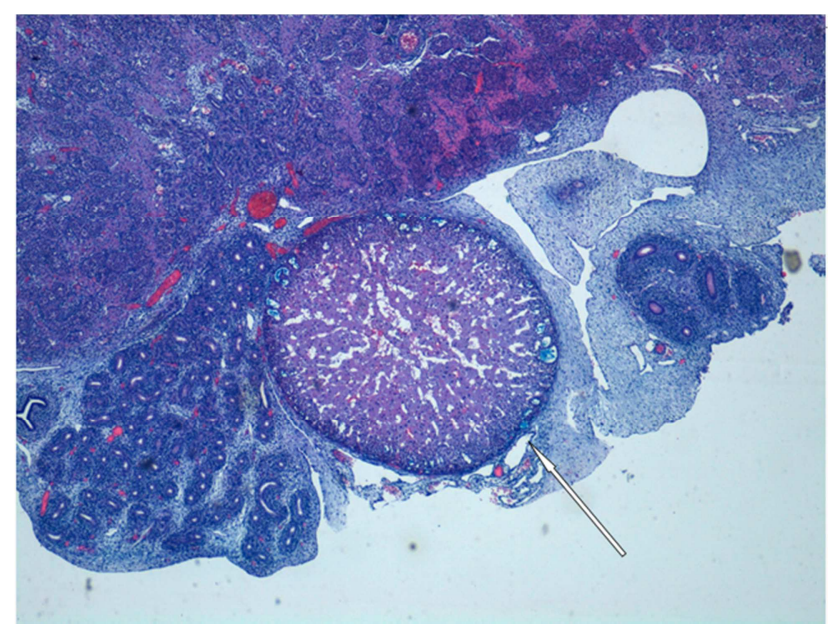

Fig. 1. Ectopic well-formed adrenal cortical gland located between testis and epididymis $(4 X)$.

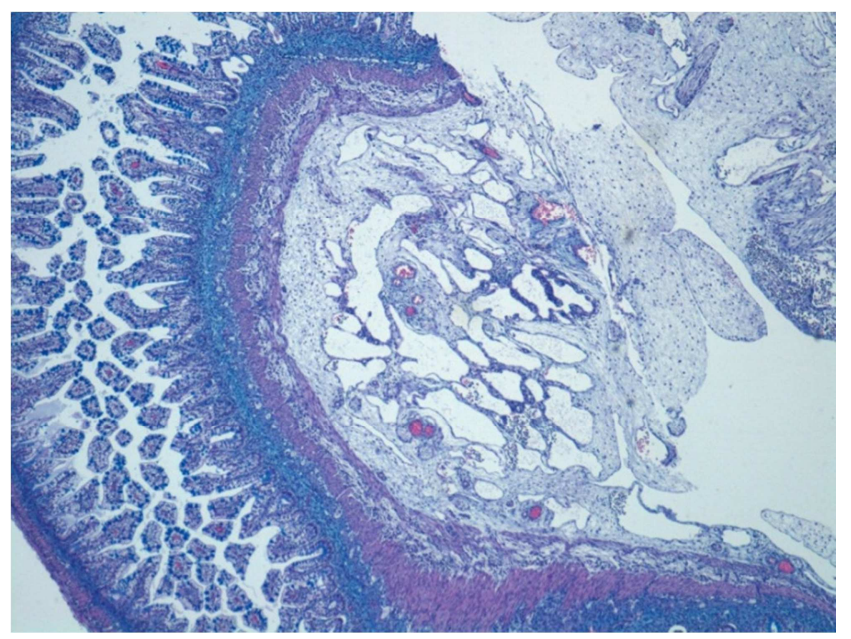

Fig. 2. Peritoneal lymphangioma consisting of amartomatous lymphatic vessels located in soft peritoneal tissue near intestinal loops (4X).

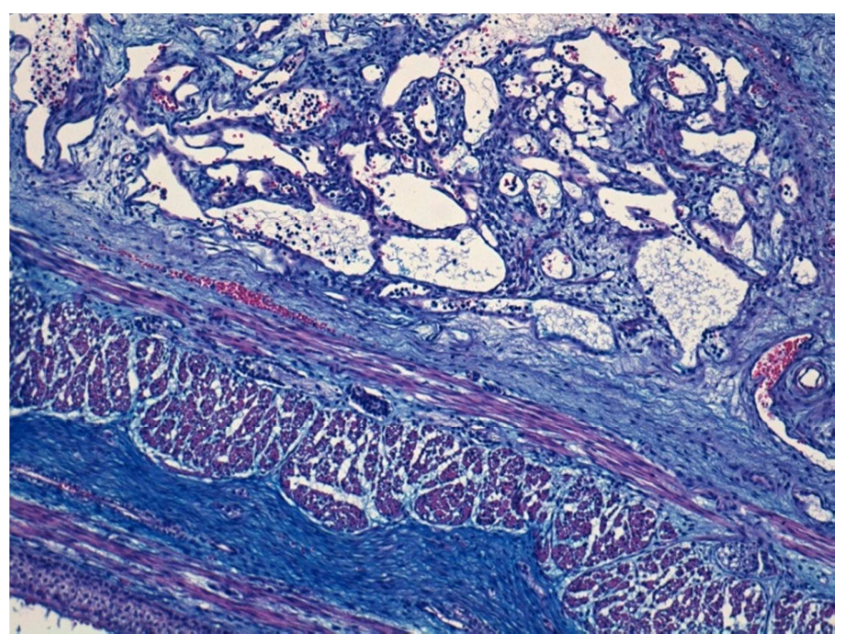

Fig. 3. Chest lymphangioma located in the context of the wall of the ascending aorta (10X).

\section{Discussion}

Ectopic adrenal tissue is a relatively common incidental finding in childhood especially during groin surgery. International literature reports an incidence of this anatomic phenomenon varying from $1 \%$ and $9,3 \%$ [3]. Adrenal rests have been described in retroperitoneum, ovaries and uterine ligaments in female and above all in inguinal region in infants and young males.

Adrenal ectopic tissue has been reported within testis or between testis and epididymis in scrotal or inguinal retention during early childhood in a percentage ranging between $7.5 \%$ and $15 \%$ [5], with spontaneous regression in the most of the cases. Only rare pathological conditions originating in ectopic adrenals have been described, above all endocrine dysfunction related to adrenal hyperfunction. In very rare cases tumors originated from ectopic adrenal tissue were reported, such as a neuroblastoma in ectopic glands of a little child [6].

Pathogenesis of this phenomenon is linked to embryological gonadic origins. In fact, adrenal cortical tissue arises from a mesothelial zone near to the urogenital ridge in the mesodermal sheet. During the organogenesis, immature cortical adrenals place on the kidneys, while immature gonads migrate in inguinal region. Between the seventh and the eighth week of gestation, cells from the neural crest migrate into the center of the early adrenal cortex to form the medulla. This phenomenon is easily identified, because it's possible to see clusters of small hyperchromic cells into adrenal cortex through microscopic examinations of internal organs in died fetus even during second gestational trimester. It is conceivable that there can be some factors able to change the process of tissue migration during late embryogenesis and early organogenesis. Ectopic cortical adrenal tissue in pelvic region must be considered a consequence of this abnormal migration. 


\section{Conclusions}

Despite several cases in childhood have been described, very few findings of ectopic adrenal gland in perinatal pathology have been reported in literature. A case of ectopic inguinal and paratesticular bilateral adrenals was presented in a sirenomelic fetus [7], but no similar finding has been reported in fetuses without other malformations.

Our case regards a male fetus died at the end of the second gestational trimester for maternal infection. Clinical examination and serological values on maternal blood were compatible with maternal and placental infection, in contrast with the negativity for the search of the most common bacterial or viral infectious agents. In absence of signs of chromosomal alterations and in light of maternal clinical and medical history, our histopathological report on placental tissue was consistent with a lymphocytic infiltrate probably caused by a not widespread viral agent.

Many viral maternal infections during second gestational trimester can determine fetal defects, such as rubella and cytomegalovirus $[4,8]$. Fetal damage caused by other viral agents, such as enteroviruses or parvovirus, are, however, poorly documented. We support the hypothesis that the autopsy findings reported in our case can be attributed to a viral maternal infection during the second trimester of gestation [9, 10]. This infectious agent would have determined an altered migration of some mesodermal tissues during organogenesis, resulting in the formation of chest and peritoneal lymphangiomas and the presence of ectopic paratesticular adrenal gland.

\section{References}

[1] Ozel S.K., Kazez A., Akpolat N. Presence of ectopic adrenocortical tissues in inguinoscrotal region suggests an association with undescended testis. Pediatric Surgery International; 23, pp. 171-175, 2007.

[2] Prada Arias M., Vázquez Castelo J. L., Montero Sánchez M., Muguerza Vellibre R., Rodríguez Costa A. Supernumerary intrascrotal ectopic spleen: discontinuous splenogonadal fusion. Anales de Pediatria; 64, pp. 277-279, 2006.

[3] Mendez R., Tellado M. G., Somoza I., Liras J., Sanchez Abuin A., Pais E., Vela D. Ectopic adrenal tissue in the spermatic cord in pediatric patiens: surgical implications. International Brazilian Journal of Urology; 32, pp. 202-207, 2006.

[4] Keeling J. W. Fetal and Neonatal Pathology. Gran Bretagna: Sprinter-Verlag Berlin Heidelberg; 1987.

[5] Dahl E. V., Bahn R. C. Aberrant adrenal cortical tissue near the testis in human infants. Section of Pathology, Mayo Foundation, Rochester, Minn; 40, pp. 587-598, 1962.

[6] Normann T., Havnen J., Mjolnerod O. Cushing's sindrome in an infant associated with neuroblastoma in two ectopic adrenal glands. Journal of Pediatric surgery; 6, pp. 169, 1971.

[7] Hadravská S., Kohoutek T. Ectopic adrenals in a sirenomelic fetus. Annals of Anatomy; 182, pp. 361-363, 2000.

[8] Sara Tremolada, Serena Delbue, and Pasquale Ferrante.Viral infection of the fetus and of the newborn infant. Pediatr Med Chir. 30(4): 177-191, 2008.

[9] Webster WS. Teratogen update: congenital rubella. Teratology 58:13-23, 1998. [PubMed: 9699240].

[10] Ghidini A, Lynch L. Prenatal diagnosis and significance of fetal infections. West J Med 159:366-373, 1993. [PubMed: 8236979]. 